\title{
An Approach to a Novel Device Agnostic Model Illustrating the Relative Change in Physical Behavior Over Time to Support Behavioral Change
}

\author{
Anna Åkerberg ${ }^{1,2}$ (D) Jan Arwald ${ }^{3} \cdot$ Anne Söderlund $^{4} \cdot$ Maria Lindén ${ }^{1}$ \\ Received: 8 November 2021 / Revised: 24 January 2022 / Accepted: 17 February 2022 / Published online: 4 March 2022 \\ (c) The Author(s) 2022
}

\begin{abstract}
Today, there is a lack of useful visual presentations of data showing progress over long time periods for users of physical activity self-monitoring devices. The aim of this paper was to present a novel theoretical model that describes the relative change in physical behavior over time and to provide examples of model application with previously collected data. Physical behavior, which includes both sedentary behavior and physical activity, was categorized into four dimensions and further processed and adjusted to fit the novel model. The model was visualized both theoretically and by using example data for two out of 20 participants, illustrating the relative change compared to baseline and trendlines for all dimensions. This approach to a novel device agnostic model can visualize the data over time and is intended to be used on an individual basis by users that need support for physical behavioral change. The model, which is based on earlier research, has flexibility and was developed to be used as a complement for data processing, to future and currently available self-monitoring devices within this arena. In the future, the novel model should be studied to see if it is valid, tested with larger samples over longer study periods, and tested for use with other self-monitoring devices to ensure its usefulness and trustworthiness.
\end{abstract}

Keywords Behavioral change $\cdot$ Dimension $\cdot$ Model $\cdot$ Physical activity $\cdot$ Physical behavior $\cdot$ Sedentary behavior

\section{Introduction}

The World Health Organization's (WHO) goal is to decrease the number of physically inactive adults by $15 \%$ by 2030 (WHO, 2018), which in practice means increasing their level of physical activity (PA) to meet the recommendations. The recommendation for adults today consists of either 150-300 min of moderate PA, 75-150 min of vigorous PA, or a combination of these two intensities (MVPA) each week, and muscle strengthening activity at least twice a week (WHO, 2020). Today, there are no globally adapted recommendations for how much light PA (LiPA) in minutes

Anna Åkerberg

anna.akerberg@fou.sormland.se

1 School of Innovation, Design and Engineering, Mälardalen University, Västerås, Sweden

2 Research and Development in Sörmland, Eskilstuna, Sweden

3 Delphie LST AB, Västerås, Sweden

4 School of Health, Care and Social Welfare, Mälardalen University, Västerås, Sweden to perform or how much sedentary time is harmful to health. A study by Heron and colleagues (2019) defined sedentary behavior (SB) as spending at least $6 \mathrm{~h}$ of waking time sedentary. However, it is recommended that all adults decrease the time spent in SB (Colberg et al., 2016; WHO, 2020) and that sedentary time can be replaced by PA of any intensity (WHO, 2020). PA is referred to as a complex behavior (Peete Gabriel et al., 2012) and can be defined as any bodily activity produced by the muscles that generates energy expenditure (Caspersen et al., 1985). A wider perspective, the concept of physical behavior (PB), includes both PA and SB that humans perform in their everyday life (Bussman \& van der Berg-Emons, 2013).

Sensor data and artificial intelligence are used today in several applications to predict, preserve, and promote a healthy life. It can also be used to analyze human behavior and responsiveness to behavior change efforts. Today, there is an increasing number of devices available for monitoring PA in everyday life. However, there are limitations regarding how the data are presented and available to the user. For example, an analog pedometer only shows the number of steps for the user in the present time, and no 
history is available. Accelerometer pedometers often show more parameters but are still limited to the present time. The activity bracelet and the smartwatch often show a wider picture and provide activity history in the related application. For example, the Fitbit application shows a history of steps, miles, floors, activity minutes, and estimated calories burned (https://www.fitbit.com/global/us/home). However, available devices today do not apply to the whole wide behavior, thus usually and mainly only applying PA in their devices. In recent years, more research has been conducted regarding SB. Although it might not be possible to just replace one behavior by the other, SB and PA are related concepts. To integrate these two concepts (SB and PA) as a whole concept, as physical behavior ( $\mathrm{PB}$ ) within the self-monitoring device, presenting all perspectives of $\mathrm{PB}$ and the relative change thereof might generate huge benefits for the user.

To meet the WHO goal by 2030, new efforts and methods are needed to be able to change PB behavior. There are a number of studies conducted in relation to increasing PA (Ball et al., 2017; Conn et al., 2011; Tuso, 2015), decreasing SB (Gardner et al., 2016; Kozey-Keadle et al., 2011; Lewis et al., 2017; Nigg et al., 2017), and that aim to monitor or change the activity pattern using different kinds of self-monitoring technologies or devices (Åkerberg et al., 2016; Bravata et al., 2007; de Vries et al., 2016; Hellstrom et al., 2018; Nigg et al., 2017; Romeo et al., 2019). There are also many cross-sectional studies performed where patterns regarding PA and/or SB are mapped or investigated on a population level in different countries (Barker et al., 2019; Hagströmer, 2007; Howitt et al., 2016; Mengesha et al., 2019).

According to Polit and Beck (2010), a model can be defined as a symbolic description of variables and interrelations among them. There is research available on different behavior models. For instance, the Integrated Behavior Change Model (Hagger \& Chatzisarantis, 2014) and a cognitive-affective model of physical activity (Loprinzi et al., 2020) are models that describe preferences or conditions for being able to make behavioral change rather than describing relative change over time when the behavioral change has already occurred. To the best of our knowledge, there are only a few studies that aim to visualize or illustrate $\mathrm{PB}$ patterns or changes thereof over time on an individual level. One study by Haga et al. (2018) aimed to visualize and describe older people's PA pattern in daily life by using VISUAL-PA software, a visual analysis tool that analyzes the intensity of PA as well as types and domains of PA, based on time-geography diaries. Today, there is no available model that can manage data from devices that measure and present $\mathrm{PB}$ patterns and relative changes in PB over time. Such a model, which can be adapted for each individual user to support behavioral change, would provide huge benefits for the user in terms of providing a tool that presents PB patterns and changes thereof in a simple way, not limited to a specific monitoring device. This in turn may increase the chance of changing the pattern of $\mathrm{PB}$ for the population to meet the WHO goal by 2030 . Therefore, the aim of this study is to present a novel theoretical model that describes changes in physical behavior over time, independent of the device used. Furthermore, the use of this novel model will be illustrated by using data from an earlier study from a behavioral change application for smartphones.

\section{Methods}

The work described in this paper contains the processing and presentation of sensor data from wearable devices, which was collected in relation to an earlier usability study (Åkerberg et al., 2018). The study was approved by the Ethical Board in Uppsala, Sweden (ref. 2013/072).

\section{The Proposed Novel Theoretical Model}

In this work, an approach to a theoretical model (Polit \& Beck, 2010) is proposed that can be used when describing the relative change in PB over time. The work in this paper has been inspired by several studies about concepts. First, the behavior dimensions can be mentioned, where Alberto and Troutman (2003) have identified six dimensions through which human behavior may occur: rate, duration, latency, topography, force, and locus. Furthermore, according to Strath and colleagues (2013), PA can be categorized into four dimensions: mode, frequency, duration, and intensity. Mode can be exemplified as the performed activity, for instance, walking or running. Frequency can refer to the number of sessions performed, for example, two sessions per week. The time of activity during a specific time frame, for example, 30 min per week, can be referred to as duration. Intensity is the rate of energy expenditure during the activity. Finally, the work by Haga et al. (2018) presents the software VISUAL-PA, aiming to visualize the PA pattern in daily life for elderly people, which is in line with the present work other than the actual target group.

\section{Sample}

The sample consisted of 20 adults (physically inactive according to WHO definition) who were recruited to participate in an earlier study (name deleted to maintain the integrity of the review process). Out of 20 participants, five were randomly selected of which two are provided as examples in this paper (A and B). 


\section{Measurements and Devices}

In this study, acceleration was measured by the App\&Move smartphone application. App\&Move (v.1.8, 2018, owned by Mälardalen University, Västerås, Sweden, and developed in cooperation with Delphie LST AB, Västerås, Sweden) can be defined as a behavioral change application. For this work, App\&Move was chosen for several reasons: to enable a deepening of the development of the application, because it targets physically inactive people, was based on actual user needs and because it has integrated behavior change strategies. The development and usability test of the App\&Move has been described elsewhere (Åkerberg et al. 2018).

\section{Collection Protocol and Data Processing Criteria}

App\&Move measures raw acceleration by sampling the accelerometer in the smartphone at $50 \mathrm{~Hz}$. The raw acceleration data were calculated and processed according to the mean amplitude deviation (MAD) method. MAD, which has been used in other studies (Aittasalo et al., 2015; Vähä-Ypyä et al., 2015), describes the typical distance of data points about the mean and is measured in units of milligravity (mg).
MAD can be defined as the deviation between the sum of the mean and the median, or as follows: $\mathrm{MAD}=\sum\left|x i-x^{-}\right| / n$.

The data was divided in 5-s epochs (Aittasalo et al., 2015; Vähä-Ypyä et al., 2015), and an epoch was defined as active if exceeded 16.7 milligravity $(\mathrm{mg})$ and sedentary if less than 16.7 mg (Vähä-Ypyä et al., 2015).

\section{Procedure and Data Collection}

The participants were instructed to use App\&Move independently for four weeks (28 days) during the time awake between 06.00 and 22.00 .

\section{Statistical Analysis}

Table 1 presents the parameters used to categorize the data from App\&Move. These parameters are further used in the proposed novel theoretical model.

Two out of five participants were used as examples in the results section, and the data for the remaining three participants can be found in the supplementary material section. All data were analyzed using Microsoft Excel, and descriptive statistics in form of figures and tables were modified in Microsoft Power Point and/or Microsoft Word (v.13, Microsoft, WA, USA). No significance testing was made.

Table 1 Presentation of the parameters used to categorize the data from App\&Move, their definition, and the measure outcome/interval for each parameter

\begin{tabular}{|c|c|c|}
\hline Parameter & Definition & Measure outcome/interval \\
\hline SB minutes & $\begin{array}{l}\text { Defined as the number of } 5 \text {-s epochs less than } 16.7 \mathrm{mg} \text {. } \\
\text { All of those epochs were added for each week, and } \\
\text { thereafter divided by } 12 \text { to be presented in minutes. The } \\
\text { data was rounded to the nearest full minute. }\end{array}$ & Presented as the total number of minutes per week. \\
\hline PA minutes & $\begin{array}{l}\text { Defined as the number of } 5 \text {-s epochs } \geq 16.7 \mathrm{mg} \text {. All of } \\
\text { those epochs were added for each week, and thereafter } \\
\text { divided by } 12 \text { to be presented in minutes. The data was } \\
\text { rounded to the nearest full minute. }\end{array}$ & Presented as the total number of minutes per week \\
\hline SB periods & $\begin{array}{l}\text { A continuously performed period of } \mathrm{SB} \text {, defined as 5-s } \\
\text { epochs less than } 16.7 \mathrm{mg} \text {, summed up to whole minutes, } \\
\text { and rounded to the nearest full minute. The period } \\
\text { breaks if the user is physically active for } 30 \mathrm{~s} \text { or more. }\end{array}$ & $\begin{array}{l}\text { Presented as the number of periods in the following } \\
\text { inter- } \\
\text { vals: }<30,>30<60,>60<120,>120<180, \geq 180 \mathrm{~min}\end{array}$ \\
\hline PA periods & $\begin{array}{l}\text { A continuously performed period of PA, defined as } 5 \text {-s } \\
\text { epochs } \geq 16.7 \mathrm{mg} \text {, summed up to whole minutes, and } \\
\text { rounded to the nearest full minute. The period breaks if } \\
\text { the user is sedentary for } 30 \mathrm{~s} \text { or more. }\end{array}$ & $\begin{array}{l}\text { Presented as the number of periods in the following } \\
\text { intervals: } 1 \leq 5,>5<10,>10<30,>30 \mathrm{~min}\end{array}$ \\
\hline The longest $S B$ period & $\begin{array}{l}\text { Defined as the longest continuously performed SB period } \\
\text { each day, defined as 5-s epochs less than } 16.7 \mathrm{mg} \text {, } \\
\text { summed up to whole minutes, and rounded to the nearest } \\
\text { full minute. The period breaks if the user is physically } \\
\text { active for } 30 \mathrm{~s} \text { or more. }\end{array}$ & Presented as the mean number of minutes per week. \\
\hline Longest PA period & $\begin{array}{l}\text { Defined as the longest continuously performed PA period } \\
\text { each day, defined as } 5 \text {-s epochs } \geq 16.7 \mathrm{mg} \text {, summed up to } \\
\text { whole minutes, and rounded to the nearest full minute. } \\
\text { The period breaks if the user is sedentary for } 30 \mathrm{~s} \text { or } \\
\text { more. }\end{array}$ & Presented as the mean number of minutes per week. \\
\hline
\end{tabular}




\section{Results}

The results are presented in two sections: the theoretical model and the theoretical model illustrated.

\section{The Theoretical Model}

The theoretical model was developed as follows: the parameters used to categorize the data from App\&Move (Table 1) were further processed according to the PA dimensions presented by Strath et al. (2013) and further modified. To illustrate and describe the change in PB over time, these PA dimensions were adopted for both SB and PA. Figure 1 illustrates the steps in the current study, the starting point, processing, the novel model, and the target group and application.

The starting point in this work is illustrated in Fig. 1. PB, including both SB and PA, is categorized into four dimensions (mode, frequency, duration, and intensity) and further adjusted mathematically to fit into the novel model, the PB dimension model, which presents the relative change in PB over time. Stages of change (SOC) is a theory that is used to identify the ability to change a behavior by mapping different levels of behavioral change in relation to how willing the individual is to make behavioral change (Prochaska \& DiClemente, 1982; 1983; and 1986). The theoretical version of the PB dimensions model is illustrated in Fig. 2.

The first column, Dimension (1), presents the four dimensions. The second column, Output (2), shows that each of the four dimensions is categorized in both SB and PA. The categorized data can be described in different units, which are shown in the third column, Unit (3). In the next column,
Baseline (4) presents the first measurement point, which is also the baseline measure. Except for Mode, which is presented as a pie chart with numbers in percentage for SB and $\mathrm{PA}$, the baseline measure is presented as total values per week. This theoretical illustration of the model shows three more measurement points (columns 5-7). At these measurement points, the data are presented as \pm the relative change in comparison to the baseline measure and in total values per week in brackets. Column 7 shows the last measurement point, which is the end line. The model can be individually adjusted both horizontally (number of measurement points/ the time columns) and vertically (number of intervals within each dimension/the unit columns), depending on special needs. The measurement points (the time columns) can also be adjusted according to special needs, for example, 1 day, 1 week, 2 weeks, 1 month, or one-quarter. To the end of each line, the model shows a trendline (8) showing the direction of progress from baseline compared to the end line.

\section{Processing and Adjustments of the Data}

The following section describes how the categorization of data was made according to the four dimensions and how the data within each dimension were processed and mathematically adjusted to fit into the novel theoretical model.

\section{Mode}

The collected data from App\&Move could be categorized as sedentary (SB) or active (PA), with a maximum of $960 \mathrm{~min}$ per day (16 h) (see Table 1, SB minutes and PA minutes). First, the total minutes per week were calculated for both SB and PA separately, and thereafter, the total minutes (SB
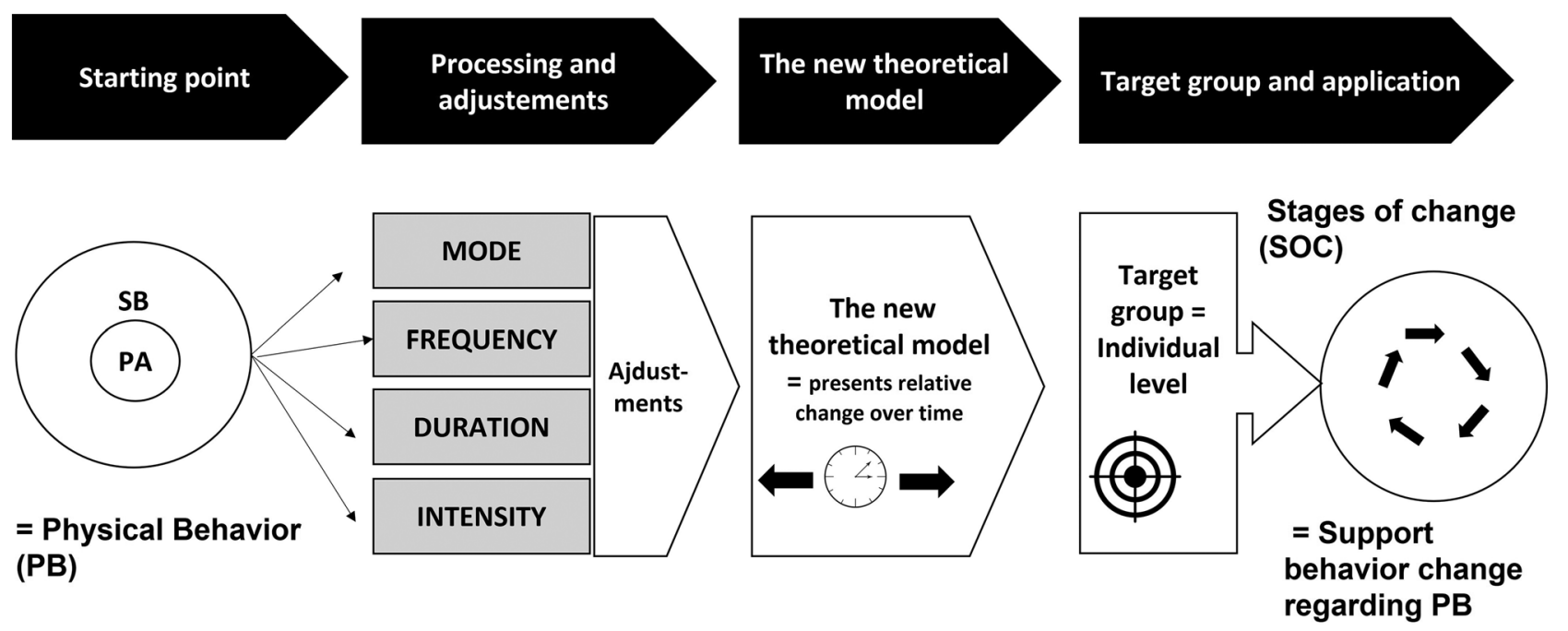

Fig. 1 Illustration of the steps in the current study: the starting point, the processing and adjustments, the novel model, and its target group and application 


\begin{tabular}{|c|c|c|c|c|c|c|c|}
\hline $\begin{array}{c}\text { Dimension } \\
\text { (1) }\end{array}$ & $\begin{array}{l}\text { Output } \\
\text { (2) }\end{array}$ & $\begin{array}{l}\text { Unit } \\
\text { (3) }\end{array}$ & $\begin{array}{l}\text { Baseline } \\
\text { (4) }\end{array}$ & (5) & (6) & $\begin{array}{l}\text { End line } \\
\text { (7) }\end{array}$ & $\begin{array}{c}\text { Trendline } \\
\text { (8) }\end{array}$ \\
\hline \multirow[t]{2}{*}{ MODE } & SB & $\%$ & & & $\cdots \cdots$ & & \\
\hline & PA & $\%$ & & & & & \\
\hline \multirow{4}{*}{ FREQUENCY } & \multirow[t]{2}{*}{ SB } & Interval & $\begin{array}{l}\text { Total values } \\
\text { /week }\end{array}$ & $\begin{array}{l}\text { I Relative } \\
\text { change } \\
\text { (total values / } \\
\text { week) }\end{array}$ & $\ldots$. & $\begin{array}{l}\text { I Relative } \\
\text { change } \\
\text { (total values / } \\
\text { week) } \\
\end{array}$ & Trendline $\rightarrow$ \\
\hline & & $\ldots .$. & $\ldots$. & $\ldots$. & $\ldots$. & $\ldots$. & $\ldots$. \\
\hline & \multirow[t]{2}{*}{ PA } & Interval & $\ldots$ & $\ldots$. & $\ldots$ & $\ldots$. & $\ldots$ \\
\hline & & $\ldots$. & $\ldots$ & $\ldots$ & $\ldots$ & $\ldots$ & $\ldots$ \\
\hline \multirow{4}{*}{ DURATION } & \multirow[t]{2}{*}{ SB } & Minutes & $\ldots$. & $\ldots$. & $\ldots$ & $\ldots$. & $\ldots$. \\
\hline & & $\ldots$ & $\ldots$ & $\ldots$. & $\ldots$. & $\ldots$. & $\ldots$. \\
\hline & \multirow[t]{2}{*}{ PA } & Minutes & $\ldots$. & $\ldots$. & $\ldots$. & $\ldots$. & $\ldots$ \\
\hline & & $\ldots$. & $\ldots$. & $\ldots$. & $\ldots$. & $\ldots$. & $\ldots$. \\
\hline \multirow{4}{*}{ INTENSITY } & \multirow[t]{2}{*}{ SB } & Minutes & $\ldots$ & $\ldots$ & $\ldots$ & $\ldots$ & $\ldots$ \\
\hline & & $\ldots$ & $\ldots$ & $\ldots$. & $\ldots$ & $\ldots$. & $\ldots$. \\
\hline & \multirow[t]{2}{*}{ PA } & Minutes & $\ldots$ & $\ldots$. & $\ldots$ & $\ldots$. & $\ldots$. \\
\hline & & $\ldots$ & $\ldots$ & $\ldots$. & $\ldots$ & $\ldots$. & $\ldots$. \\
\hline
\end{tabular}

Fig. 2 Illustration of the theoretical version of the PB dimension model

and PA) for each week were calculated. The percentages of SB and PA are presented in the same pie chart, with one pie chart for each measurement point (columns 4-7).

\section{Frequency}

Frequency was defined as the number of continuously performed periods of SB (SB periods) and periods of PA (PA periods) (see Table 1, SB periods and PA periods). The periods were calculated for different lengths of time intervals, from under 30 min until over $180 \mathrm{~min}$ for SB and from $1 \mathrm{~min}$ until over $30 \mathrm{~min}$ for PA. The baseline measure corresponds to the total number of periods for each week within the chosen interval and is presented as total values per week (number of periods). The remaining measurement points (columns 5-7) present the relative change in percentage in comparison to baseline and the total value for that measurement point in brackets. A trendline shows the direction of change from baseline to the end line.

\section{Duration}

Duration was defined as the total number of sedentary (SB minutes) and active minutes (PA min), respectively, presented as total minutes per week (see Table 1, SB minutes and PA minutes) and by the longest continuously performed period of both SB and PA in mean minutes per week (see Table 1, Longest SB period and Longest PA period). The baseline measure corresponds to the total value per week. The remaining measurement points (columns 5-7) present the relative change in percentage in comparison to baseline. A trendline shows the direction of change from baseline to the end line. The longest periods were calculated as the mean of the longest period of each week, corresponding to the baseline measurement (column 4). The remaining measurement points (columns 5-7) present the relative change in percentage in comparison to baseline and the total value for that measurement point in brackets. A trendline shows the direction of change from baseline to the end line.

\section{Intensity}

Data used for intensity in this work were the PA data (see Table 1, PA minutes). Two different intensities of PA were calculated: light PA (LiPA) and moderate to vigorous PA (MVPA). The categorization of the intensities was made by filtering the data according to the mean amplitude deviation (MAD) method. The following cut point thresholds (mg) were used: $\mathrm{LiPA}=16.7-331.1 \mathrm{mg}, \mathrm{MVPA}=>331.1 \mathrm{mg}$. The baseline measure (column 4) corresponds to the total 
value per week. The remaining measurement points (columns 5-7) present the relative change in percentage in comparison to baseline and the total value for that measurement point in brackets. A trendline shows the direction of change from baseline to the end line.

\section{The Theoretical Model Illustrated}

The PB dimension model is illustrated in Figs. 3 and 4 for participants A and B, respectively, and can be seen in the supplementary material for participants C-E. One week was

Participant A

\begin{tabular}{|c|c|c|c|c|c|c|c|}
\hline $\begin{array}{c}\text { Dimension } \\
\text { (1) }\end{array}$ & $\begin{array}{l}\text { Output } \\
\text { (2) }\end{array}$ & $\begin{array}{l}\text { Unit } \\
\text { (3) }\end{array}$ & $\begin{array}{c}\text { Baseline } \\
\text { (4) }\end{array}$ & (5) & (6) & $\begin{array}{l}\text { End line } \\
\text { (7) }\end{array}$ & $\begin{array}{l}\text { Trendline } \\
\text { (8) }\end{array}$ \\
\hline \multirow[t]{2}{*}{ MODE } & SB & $\%$ & & & & & \\
\hline & PA & $\%$ & 97 & 92 & & 95 & \\
\hline \multirow{9}{*}{ FREQUENCY } & \multirow{5}{*}{ SB } & $<30$ & 149 & $\begin{array}{l}+123 \% \\
(332)\end{array}$ & $\begin{array}{l}+194 \% \\
(438)\end{array}$ & $\begin{array}{l}+34 \% \\
(199)\end{array}$ & 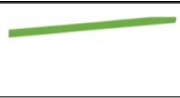 \\
\hline & & $>30<60$ & 18 & $\begin{array}{l}+6 \% \\
(19) \\
\end{array}$ & $\begin{array}{l}+56 \% \\
(28) \\
\end{array}$ & $\begin{array}{l}+11 \% \\
(20) \\
\end{array}$ & \\
\hline & & $\begin{array}{l}>60 \\
<120\end{array}$ & 10 & $\begin{array}{l}+40 \% \\
(14)\end{array}$ & $\begin{array}{l}+70 \% \\
(17)\end{array}$ & $\begin{array}{l}+80 \% \\
(18)\end{array}$ & \\
\hline & & $\begin{array}{l}>120 \\
<180 \\
\end{array}$ & 6 & $\begin{array}{l}-83 \% \\
(1)\end{array}$ & $\begin{array}{l}-100 \% \\
(0)\end{array}$ & $\begin{array}{l}-67 \% \\
(2)\end{array}$ & \\
\hline & & $>180$ & 6 & $\begin{array}{l}-83 \% \\
(1)\end{array}$ & $\begin{array}{l}-100 \% \\
(0)\end{array}$ & $\begin{array}{l}+17 \% \\
(7)\end{array}$ & \\
\hline & \multirow{4}{*}{ PA } & $1<5$ & 71 & $\begin{array}{l}+32 \% \\
(97)\end{array}$ & $\begin{array}{l}+50 \% \\
(106)\end{array}$ & $\begin{array}{l}+30 \% \\
(92)\end{array}$ & \\
\hline & & $>5<10$ & 6 & $\begin{array}{l}+33 \% \\
(8)\end{array}$ & $\begin{array}{l}-17 \% \\
(5) \\
\end{array}$ & $\begin{array}{l}-17 \% \\
(5) \\
\end{array}$ & \\
\hline & & $>10<30$ & 2 & $\begin{array}{l}0 \% \\
(2)\end{array}$ & $\begin{array}{l}-50 \% \\
(1)\end{array}$ & $\begin{array}{l}+100 \% \\
\text { (4) }\end{array}$ & \\
\hline & & $>30$ & 0 & $\begin{array}{l}0 \% \\
(0)\end{array}$ & $\begin{array}{l}0 \% \\
(0) \\
\end{array}$ & $\begin{array}{l}0 \% \\
(0) \\
\end{array}$ & \\
\hline \multirow{4}{*}{ DURATION } & \multirow[t]{2}{*}{ SB } & $\begin{array}{l}\text { Total } \\
\text { minutes }\end{array}$ & 6347 & $\begin{array}{l}-36 \% \\
(4071)\end{array}$ & $\begin{array}{l}-18 \% \\
(5232)\end{array}$ & $\begin{array}{l}-14 \% \\
(5463)\end{array}$ & \\
\hline & & $\begin{array}{l}\text { Longest } \\
\text { SB }\end{array}$ & 356 & $\begin{array}{l}-71 \% \\
(105) \\
\end{array}$ & $\begin{array}{l}-74 \% \\
(94) \\
\end{array}$ & $\begin{array}{l}-38 \% \\
(222) \\
\end{array}$ & $=$ \\
\hline & \multirow[t]{2}{*}{ PA } & $\begin{array}{l}\text { Total } \\
\text { minutes }\end{array}$ & 221 & $\begin{array}{l}+67 \% \\
(370) \\
\end{array}$ & $\begin{array}{l}+58 \% \\
(349) \\
\end{array}$ & $\begin{array}{l}+42 \% \\
(313) \\
\end{array}$ & - \\
\hline & & $\begin{array}{l}\text { Longest } \\
\text { PA }\end{array}$ & 5 & $\begin{array}{l}0 \% \\
(5) \\
\end{array}$ & $\begin{array}{l}0 \% \\
(5) \\
\end{array}$ & $\begin{array}{l}+60 \% \\
(8) \\
\end{array}$ & 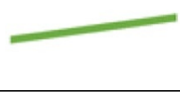 \\
\hline \multirow[b]{2}{*}{ INTENSITY } & LiPA & $\begin{array}{l}\text { Total } \\
\text { minutes }\end{array}$ & 218 & $\begin{array}{l}+61 \% \\
(352) \\
\end{array}$ & $\begin{array}{l}+53 \% \\
(334) \\
\end{array}$ & $\begin{array}{l}+40 \% \\
(306) \\
\end{array}$ & 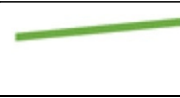 \\
\hline & MVPA & $\begin{array}{l}\text { Total } \\
\text { minutes }\end{array}$ & 3 & $\begin{array}{l}+500 \% \\
(18)\end{array}$ & $\begin{array}{l}+400 \% \\
(15)\end{array}$ & $\begin{array}{l}+133 \% \\
\text { (7) }\end{array}$ & \\
\hline
\end{tabular}

Fig. 3 Exemplification of the PB dimension model for participant A. The model includes several dimensions, outputs, units, and flexible number of measure points. The model can be summarized by the four trendlines, one for each dimension, which are presented as green (desirable outcome), red (not desirable outcome), or yellow (applied when there are no progression) 


\section{Participant B}

\begin{tabular}{|c|c|c|c|c|c|c|c|}
\hline $\begin{array}{c}\text { Dimension } \\
\text { (1) }\end{array}$ & $\begin{array}{l}\text { Output } \\
\text { (2) }\end{array}$ & $\begin{array}{l}\text { Unit } \\
(3)\end{array}$ & $\begin{array}{c}\text { Baseline } \\
\text { (4) }\end{array}$ & (5) & (6) & $\begin{array}{c}\text { End line } \\
\text { (7) }\end{array}$ & $\begin{array}{c}\text { Trendline } \\
\text { (8) }\end{array}$ \\
\hline \multirow[t]{2}{*}{ MODE } & SB & $\%$ & & 9 & 8 & & \\
\hline & PA & $\%$ & 93 & 91 & 92 & 95 & \\
\hline \multirow{9}{*}{ FREQUENCY } & \multirow{5}{*}{ SB } & $<30$ & 449 & $\begin{array}{l}+41 \% \\
(634)\end{array}$ & $\begin{array}{l}+35 \% \\
(605)\end{array}$ & $\begin{array}{l}-0,50 \% \\
(447)\end{array}$ & \\
\hline & & $>30<60$ & 23 & $\begin{array}{l}-70 \% \\
\text { (7) }\end{array}$ & $\begin{array}{l}-22 \% \\
(18)\end{array}$ & $\begin{array}{l}-26 \% \\
(17)\end{array}$ & \\
\hline & & $\begin{array}{l}>60 \\
<120\end{array}$ & 0 & $\begin{array}{l} \pm 0 \% \\
\text { (0) }\end{array}$ & $\begin{array}{l}+100 \% \\
\text { (1) }\end{array}$ & $\begin{array}{l} \pm 0 \% \\
(0)\end{array}$ & \\
\hline & & $\begin{array}{l}>120 \\
<180\end{array}$ & 0 & $\begin{array}{l} \pm 0 \% \\
\text { (0) }\end{array}$ & $\begin{array}{l} \pm 0 \% \\
\text { (0) }\end{array}$ & $\begin{array}{l}+100 \% \\
\text { (1) }\end{array}$ & \\
\hline & & $>180$ & 0 & $\begin{array}{l} \pm 0 \% \\
\text { (0) }\end{array}$ & $\begin{array}{l} \pm 0 \% \\
\text { (0) }\end{array}$ & $\begin{array}{l}+100 \% \\
\text { (1) }\end{array}$ & \\
\hline & \multirow{4}{*}{ PA } & $1<5$ & 134 & $\begin{array}{l}+19 \% \\
(159)\end{array}$ & $\begin{array}{l}+8 \% \\
(145)\end{array}$ & $\begin{array}{l}+11 \% \\
(149)\end{array}$ & \\
\hline & & $>5<10$ & 6 & $\begin{array}{l}-50 \% \\
(3)\end{array}$ & $\begin{array}{l}-83 \% \\
(1)\end{array}$ & $\begin{array}{l}-100 \% \\
(0)\end{array}$ & \\
\hline & & $>10<30$ & 9 & $\begin{array}{l}-33 \% \\
(6)\end{array}$ & $\begin{array}{l}-67 \% \\
(3)\end{array}$ & $\begin{array}{l}-100 \% \\
(0)\end{array}$ & \\
\hline & & $>30$ & 0 & $\begin{array}{l} \pm 0 \% \\
(0)\end{array}$ & $\begin{array}{l} \pm 0 \% \\
(0)\end{array}$ & $\begin{array}{l} \pm 0 \% \\
(0)\end{array}$ & \\
\hline \multirow{4}{*}{ DURATION } & \multirow[t]{2}{*}{ SB } & $\begin{array}{l}\text { Total } \\
\text { minutes }\end{array}$ & 5861 & $\begin{array}{l}-14 \% \\
(5061) \\
\end{array}$ & $\begin{array}{l}-19 \% \\
(4774)\end{array}$ & $\begin{array}{l}+0.3 \% \\
(5879)\end{array}$ & \\
\hline & & $\begin{array}{l}\text { Longest } \\
\text { SB }\end{array}$ & 42 & $\begin{array}{l}-12 \% \\
(37)\end{array}$ & $\begin{array}{l}+150 \% \\
(105)\end{array}$ & $\begin{array}{l}+212 \% \\
(131)\end{array}$ & \\
\hline & \multirow[t]{2}{*}{ PA } & $\begin{array}{l}\text { Total } \\
\text { minutes }\end{array}$ & 444 & $\begin{array}{l}+7 \% \\
(473)\end{array}$ & $\begin{array}{l}-7 \% \\
(415)\end{array}$ & $\begin{array}{l}-36 \% \\
(285)\end{array}$ & \\
\hline & & $\begin{array}{l}\text { Longest } \\
\text { PA }\end{array}$ & 11 & $\begin{array}{l}-91 \% \\
(1)\end{array}$ & $\begin{array}{l}-73 \% \\
(3)\end{array}$ & $\begin{array}{l}-27 \% \\
(8)\end{array}$ & \\
\hline \multirow[b]{2}{*}{ INTENSITY } & LiPA & $\begin{array}{l}\text { Total } \\
\text { minutes }\end{array}$ & 444 & $\begin{array}{l}+5 \% \\
(467)\end{array}$ & $\begin{array}{l}-8 \% \\
(407)\end{array}$ & $\begin{array}{l}-36 \% \\
(284)\end{array}$ & \\
\hline & MVPA & $\begin{array}{l}\text { Total } \\
\text { minutes }\end{array}$ & 0 & $\begin{array}{l}+600 \% \\
(6)\end{array}$ & $\begin{array}{l}+800 \% \\
(8)\end{array}$ & $\begin{array}{l}+100 \% \\
\text { (1) }\end{array}$ & \\
\hline
\end{tabular}

Fig. 4 Exemplification of the PB dimension model for participant B. The model includes several dimensions, outputs, units, and flexible number of measure points. The model can be summarized by the

chosen as the measurement interval (columns 4-7) in the illustrated model.

The first column, Dimension (1), presents the four dimensions. The second column, Output (2), shows that each of the four dimensions is categorized in both SB and PA. The four trendlines, one for each dimension, which are presented as green (desirable outcome), red (not desirable outcome), or yellow (applied when there are no progression)

categorized data can be described in different units, which is shown in the third column, Unit (3), and for some dimensions in several intervals. The next column (4) presents the first measurement point, which is also the baseline measurement. Except for Mode, which presents a pie chart with 
numbers in percentage of SB and PA, the baseline measurement is presented as the total values per week. The exemplified model of participants A and B shows three more measurement points (columns 5-7), where the data are presented as \pm the relative change in comparison to the baseline measurement and as the total values per week in brackets. Column 7 shows the last measurement point, which is the end line. To the end of each line (8), the model shows a trendline that indicates whether the progression from baseline to end line is increasing, decreasing, or no progression. The trendline shows the desirable outcome in different colors: green trendline (desirable outcome), red trendline (not desirable outcome), or yellow trendline (applied when there is no progression). The model can be summarized by the four trendlines, one for each dimension.

\section{Discussion}

This work presents the development of the novel PB dimension model that categorizes PB in four dimensions, generates relative changes in the data and illustrates the progression of trendlines, which indicates both progression and desirable outcome. Orban et al. (2012) argue that the progression that allows for awareness about PA habits is required on the individual level. They also argue that knowledge of daily activity patterns in everyday life is essential to enhance lifestyle changes. The PB dimensions model contributes information about trends and progression to the user, which do not exist in available self-monitoring devices today. The developed model is feasible to implement in any self-monitoring device supporting access to accelerometer data, such as smartphones, smart watches, or other wearable devices.

\section{The Model-Starting Point}

The starting point of this work has been to review and consider earlier presented concepts and methods of visualizing and illustrating PB patterns, or changes thereof, and build further on this. This strengthens and makes the relevance and trustworthiness of our study good. As the focus of this work relates to changing behavior, it is supported by Alberto and Troutman's (2003) work of different dimensions to study when observing behaviors that humans perform. Haga et al. (2018) developed a well-functioning software, VISUAL-PA, which focuses on elderly people and PA. The PB dimensions model presented in this paper adds important aspects to that model by having a wider perspective and adopting PB behavior as a whole and targeting a larger group-the adults. Another unique aspect of the presented PB dimension model is its ability to present the relative change in behavior over time, which VISUAL-PA (Haga et al., 2018) is not able to do. Similar to Strath and colleagues (2013), the PB dimension model categorizes PA in different dimensions. However, the PB dimension model also applies the categorization of $\mathrm{SB}$, which contributes to a wider perspective of the behavior.

\section{Components of the Model-Findings}

Regarding the components contributing to the PB dimensions model, there are several studies involving the mode dimension, which, for instance, Haga et al. (2018), has been integrated into VISUAL-PA software. Additionally, Dogra et al. (2010) investigated the physical activity mode in groups of different ethnicities in Canada. Their study concluded that minority groups and immigrants were less likely to participate in several kinds of exercises, which therefore indicated that these groups had a higher risk of future lifestyle-related illnesses. Integration mode is therefore useful since it can illustrate for the user which modes are more or less frequent and thus which changes in behavior are needed. In this version of the PB dimension model, a simpler version of the mode dimension was able to show the distribution in percentage between SB and PA over time in a pie chart on a weekly basis. According to the mode dimension in Figs. 3 and 4, both participants are sedentary, according to the definition by Heron and colleagues (2019), because their total SB time exceeds more than $6 \mathrm{~h}$. Participant $\mathrm{B}$ showed a desirable negative progression from baseline to end line for both $\mathrm{SB}$ and PA. For participant A, the mode dimension indicates a desirable positive progression for SB from baseline to end line. The same pattern is shown for PA which is a small but positive increase. This result indicates that even a small development can work as motivation to continue and maintain to make behavioral change.

The frequency dimension was defined as SB and PA periods in this work, which have been frequently studied by other researchers. For instance, Rutten and colleagues (2013) worked with the STUFF intervention, focusing on people breaking long periods of sitting with 5 min of standing. An increasing number of short periods can indicate that the user is actively working to break SB often, which is a desirable progress. Also, a decrease in the longer SB periods is a desirable outcome. An interval of periods can be useful and important baseline information to relate to over a longer time period, for instance, over 6 months, to be able to see changes in the PB pattern. However, a challenge was how to define a continuously performed period, i.e., how much interruption was allowed and still define the period as a continuously performed period. For instance, a study by Ezeugwu et al. (2015) applies a 2-min interruption in activity and sedentary periods. However, the target group in their study was adults diagnosed with multiple sclerosis who often have problems with speed of movements. Because the target group 
of physically inactive adults in our work was assumed to be healthy, a shorter interruption can be reasonable, motivating the 30-s limit. This means that in an SB period, the user can stand up and take a couple of steps and sit down again if this interruption does not exceed $30 \mathrm{~s}$, and the opposite is true for PA periods. When studying the frequency dimension in Fig. 3, it can be seen that participant $\mathrm{A}$ has an increase in the number of 1-5-min PA periods and 10-30-min periods, which is positive and may be a result of more frequently made shorter breaks. Participant A also showed a desirable outcome for most of the SB periods, which was a positive development. Figure 4 shows negative results or no progression regarding SB periods for participant $B$. However, similar to participant A, participant $\mathrm{B}$ also shows positive results regarding the shorter breaks (1-5-min periods of PA).

In this work, duration was defined as the total number of SB and PA minutes. Duration has been frequently studied regarding both PA, mostly regarding steps (Åkerberg et al., 2012, 2016; Schneider et al., 2003; Tudor-Locke et al., 2011) but also regarding SB, where mostly hours spent in SB have been the main outcome (Bond et al., 2014; Du et al., 2019; Ekelund et al., 2016). In available PA devices, duration is mainly defined as the total number of steps per day. However, some devices use minutes as the main outcome (name deleted to maintain the integrity of the review process), or as part of measure outcomes, such as more advanced Fitbit devices (https://www.fitbit. $\mathrm{com} / \mathrm{global} / \mathrm{us} / \mathrm{home})$. Although duration is frequently used in self-monitoring devices today, applying the relative change of the duration is not as common. According to the duration dimension in Figs. 3 and 4, the numbers regarding SB minutes, longest SB period, PA minutes, and longest PA period can indicate desirable or not desirable progression over time, which therefore is important to be aware of to be able to make progress in the future.

Intensity is also frequently used in research and devices, for instance, in VISUAL-PA software (Haga et al., 2018) and by Lyden and colleagues (2017). Bakrania and colleagues (2016) claim that the classification of SBs and light physical activity should be broadly comparable between different studies, irrespective of the device brand used. Overall, investigating intensity is a challenge due to a lack of standards in classifying the intensity. In this study, the intensity of PA was defined as LIPA and MVPA. Because one of the ambitions of the PB dimension model is that it should be device agnostic, the MAD method was used to categorize intensity. The MAD method is less sensitive to systematic errors, and it thus becomes more independent of the selected measuring equipment. Figure 3 shows that participant A shows progression regarding PA intensity, both regarding LiPA and MVPA from baseline to end line. Participant B, however, indicates a decrease in LiPA but an increase in MVPA.

\section{The Model-Strengths}

A considerable advantage of the proposed model is that although the work has been exemplified by using data from App\&Move, the idea is to apply and use the model for other devices that measure SB and/or PA by acceleration. Kozey Keadle and colleagues (2019) argue that there is a problem in estimating and processing data from different devices. To be able to adopt the PB dimension model to available or future devices is therefore a strength. The PB dimensions model was developed for an individual level, for example, to be used by health and wellness coaches or physiotherapists in their work to support single individuals in behavioral change regarding PB. The PB dimension model is based on earlier studies but should be tested on several more groups of people in the population. From a public health perspective, the most benefits are gained from targeting the groups in the population that are the least physically active (Hagströmer \& Franzen, 2017; Warburton et al., 2006), which motivates using App\&Move and the PB dimension model on other physically inactive groups in the population, for instance, vulnerable individuals such as elderly individuals or people with different impairments, mental illness, or depression. Another strength of the PB dimension model is its flexibility; it is possible to choose the number of measurement points, to define the measurement points, for example, 1 day, 1 week, 2 weeks, and 1 month. It is also possible to adjust the number of levels for each dimension, depending on how many intervals or how many intensities are useful. The expected outcome when using the model for a longer period of time could be to see the progression to no longer be defined as sedentary and/or to fulfill the PA recommendations from the WHO.

\section{The Model-Limitations}

Some limitations have to be mentioned. This application of the PB dimension model has been illustrated with data from two out of five randomly selected participants out of the sample of 20 . This sample size can be a limitation and can have affected the results; therefore, further studies with larger samples are needed. However, our study aimed to present the development of this novel model as a starting point for a new method, and therefore, the results from the measurements are not the main outcome. Because of the short study period of 4 weeks, only a small progression, if any, was expected. A study period of at least 12 weeks, preferably 26 weeks, is needed for the target group to make behavioral change. In that case, the PB dimension model could have shown a greater relative change over time. Furthermore, a possible limitation with the novel PB dimensions model is that the present version is not able to identify the mode dimension on a detailed level. However, the model 
is transparent to the user and does not require any other data collection methods, such as diaries, which may therefore be an advantage.

The application of the PB dimension model has been illustrated with data from the behavioral change application App\&Move (Åkerberg et al. 2018; Åkerberg \& Arwald, 2019), which only requires a smartphone. The App\&Move data were collected from a free-living environment and this method has probably been mirroring their life more accurately than subjective data collection methods or tests in a laboratory.

\section{The Model-Future Research and Development}

In future versions of the $\mathrm{PB}$ dimension model, a more detailed picture of the mode would be interesting to identify, for instance, if the user is lying down, sitting, standing, walking, or running, for example, in combination with artificial intelligence or movement recognition. Intensity for SB was not possible to identify; however, it would have been useful to be able to identify intensity even for SB, especially to investigate adherence to the device, i.e., whether the smartphone was lying still somewhere (no use) or if it was carried by the user (use). Another aspect to work on in the future is the intensity thresholds, which were challenging, and the thresholds we used could have affected the outcome of the model. It was not possible to filter out some movement, for example, when the user did not carry the smartphone under a longer period of time. Specifically, the missing data were difficult to analyze whether the user carried the smartphone or not. This interpretation affects the way the SB and PA periods were analyzed when data were missing between two connected periods. Additionally, to validate the usefulness of the model, it would be preferable, for example, to test the model in clinical practice. A next step could be to apply this model to other self-monitoring devices within the area, which could contribute to the model being widely useful.

\section{Conclusion}

This paper presents an approach of a novel device agnostic model, the physical behavior (PB) dimension model, that describes changes in PB, including both sedentary behavior and physical activity, over time. The work describes how the data have been categorized, processed, and adjusted to fit into the novel model, and the model has been visualized both theoretically and based on the example of two out of 20 participants from earlier collected data. The PB dimension model visualizes the data over time and aims to be used on an individual level by users who need support in behavioral change regarding physical behavior. The model, which is based on earlier research, has flexibility and was developed as a complement for data processing, to future and available devices within the area. For the future, the novel model should be studied to see if it is valid, tested with larger samples over longer study periods and tested for use with other self-monitoring devices to ensure its usefulness and trustworthiness.

Supplementary Information The online version contains supplementary material available at https://doi.org/10.1007/s41347-022-00246-6.

Funding Open access funding provided by Mälardalen University. This study was supported by ESS-H + (Embedded Sensor Systems for Health +) funded by the KKS (The Swedish Knowledge Foundation).

\section{Declarations}

Ethics Approval The study was approved by the Swedish Ethical board, Dnr: 2013/072.

Conflict of Interest The authors declare no competing interests.

Open Access This article is licensed under a Creative Commons Attribution 4.0 International License, which permits use, sharing, adaptation, distribution and reproduction in any medium or format, as long as you give appropriate credit to the original author(s) and the source, provide a link to the Creative Commons licence, and indicate if changes were made. The images or other third party material in this article are included in the article's Creative Commons licence, unless indicated otherwise in a credit line to the material. If material is not included in the article's Creative Commons licence and your intended use is not permitted by statutory regulation or exceeds the permitted use, you will need to obtain permission directly from the copyright holder. To view a copy of this licence, visit http://creativecommons.org/licenses/by/4.0/.

\section{References}

Aittasalo, M., Vähä-Ypyä, H., Vasankari, T., Husu, P., Jussila, A. M., \& Sievänen, H. (2015). Mean amplitude deviation calculated from raw acceleration data: A novel method for classifying the intensity of adolescents' physical activity irrespective of accelerometer brand. BMC Sports Science, Medicine and Rehabilitation, 7, 18.

Åkerberg, A., Linden, M., Folke, M. (2012). How accurate are pedometer cell phone applications? A comparison between six applications. CENTERIS 2012 - Conference on ENTERprise Information Systems / HCIST 2012 - International Conference, on Health and Social Care Information Systems and Technologies. Procedia Technology, 5, 787-792. Portugal 2012.

Åkerberg, A., Söderlund, A., \& Linden, M. (2016). Investigation of the validity and reliability of a smartphone pedometer application. European Journal of Physiotherapy, 18(3), 185-193.

Åkerberg, A., Söderlund, A., \& Linden, M. (2018). The development and usability testing of an interactive health technology solution, for encouragement of physical activity in inactive adults based on the user perspective. Journal of Technology in Behavioral Science, 4, 93-105.

Åkerberg, A., Arwald, J. (2019). Effects on physical activity duration with a digital behavior change tool. ICAMPAM2019, 6th International conference on ambulatory monitoring of physical activity and movement, 26-28 June 2019, Maastricht, Netherlands. 
Alberto, P. A., Troutman, A. C. (2003). Applied behavior analysis for teachers. Sixth edition.

Ball, K., Hunter, R. F., Maple, J. L., Moodie, M., Salmon, J., Ong, K. L., Stephens, L. D., Jackson, M., \& Crawford, D. (2017). Can an incentive-based intervention increase physical activity and reduce sitting among adults? The ACHIEVE (Active ChoicesIncEntiVE) feasibility study. International Journal of Behavioral Nutrition and Physical Activity, 14, 35. https://doi.org/10.1186/ s12966-017-0490-2

Barker, J., Smith Byrne, K., Doherty, A., Foster, C., Rahimi, K., Ramakrishnan, R., Woodward, M., Dwyer, T. (2019). Physical activity of UK adults with chronic disease: Cross-sectional analysis of accelerometer-measured physical activity in 96706 UK Biobank participants. International Journal of Epidemiology, 1167-1174.

Bakrania, K., Yates, T., Rowlands, A. V., Esliger, D. W., Bunnewell, S., Sanders, J., Davies, M., Khunti, K., Edwardson, C. L. (2016), Intensity thresholds on raw acceleration data: Euclidean norm minus one (ENMO) and mean amplitude deviation (MAD) approaches. PLoS One, 11(10).

Bond, D. S., Thomas, J. G., Raynor, H. A., Moon, J., Sieling, J., Trautvetter, J., Leblond, T., Wing, R. R. (2014). B-MOBILE - A smartphone-based intervention to reduce sedentary time in overweight/obese individuals: A within-subjects experimental trial. PLoS One, 9(6), e100821.

Bravata, D. M., Smith-Spangler, C., Sundaram, V., et al. (2007). Using pedometers to increase physical activity and improve health. $A$ Systematic Review. JAMA, 298, 19.

Bussman, J. B. J., \& van der Berg-Emons, R. J. G. (2013). To total amount of activity .... and beyond: Perspectives on measuring physical behavior. Frontiers in Psychology, 4, 1-6.

Caspersen, C. J., Powell, K. E., \& Christenson, G. M. (1985). Physical activity, exercise and physical fitness: Definitions and distinctions for health related research. Public Health Reports, 100(2), 126-131.

Colberg, S. R., Sigal, R. J., Yardley, J. E., Riddell, M. C., Dunstan, D. W., Dempsey, P. C., Horton, E. S., Castorino, K., \& Tate, D. F. (2016). Physical activity/exercise and diabetes: A position statement of the American Diabetes Association. Diabetes Care, 39, 2065-2079.

Conn, V. S., Hafdahl, A. R., \& Mehr, D. R. (2011). Interventions to increase physical activity among healthy adults: Meta-analysis of outcomes. American Journal of Public Health, 101(4), 751-758.

de Vries, H. J., Kooiman, T. J. M., van Ittersum, M. W., van Brussel, M., \& de Groot, M. (2016). Do activity monitors increase physical activity in adults with overweight or obesity? A Systematic Review and Meta-Analysis. Obesity, 24(19), 2078-2091.

Dogra, S., Meisner, B. A., Ardern, C. I. (2010). Variation in mode of physical activity by ethnicity and time since immigration: A crosssectional analysis. International Journal of Behavioral Nutrition and Physical Activity, 7(75).

Du, Y., Liu, B., Sun, Y., Snetselaar, L. G., Wallace, R. B., Bao, W. (2019). Trends in adherence to the physical activity guidelines for Americans for aerobic activity and time spent on sedentary behavior among US adults, 2007 to 2016. JAMA Network Open, 3;2(7), e197597.

Ekelund, U., Steene-Johannessen, J., Brown, W. J., Wang Fagerland, M., Owen, N., Powell, K. E., Bauman, A., \& Lee, I. M. (2016). Does physical activity attenuate, or even eliminate, the detrimental association of sitting time with mortality? A harmonised metaanalysis of data from more than 1 million men and women. Lancet, 388(10051), 1302-1310.

Ezeugwu, V., Klaren, R. E., Hubbard, E. A., Manns, P., \& Motl, R. W. (2015). Mobility disability and the pattern of accelerometerderived sedentary and physical activity behaviors in people with multiple sclerosis. Preventive Medicine Reports, 2, 241-246.
Gardner, B., Smith, L., Lorencattod, F., Hamere, M., \& Biddlef, S. J. H. (2016). How to reduce sitting time? A review of behaviour change strategies used in sedentary behaviour reduction interventions among adults. Health Psychology Review, 10(1), 89-112.

Haga, M., Vrotsou, K., \& Bredland, E. (2018). Visualizing physical activity patterns among community-dwelling older adults: A pilot study. Sports (basel), 6(4), 135. https://doi.org/10.3390/ sports6040135

Hagger, S., \& Chatzisarantis, N. L. D. (2014) An integrated behavior change model for physical activity. Exercise and Sport Sciences Reviews, 42(2), 62 Y69.

Hagströmer, M. (2007). Assessment of health-enhancing physical activity at population level. Doctoral Thesis, the department of bioscience and nutrition, unit of preventive nutrition, Karolinska Institute, Stockholm.

Hagströmer, M., \& Franzen, E. (2017). The importance of physical activity and health for physical therapy. Physical Therapy Reviews, 22, 3-4.

Hellstrom, P. A. R., Åkerberg, A., Ekström, M., \& Folke, M. (2018). Evaluation of the Ing VaL pedobarography system for monitoring of walking speed. Health Inform Res., 24(2), 118-124.

Heron, L., O'Neill, C., McAneney, H., Kee, F., \& Tully, M. A. (2019). Direct healthcare costs of sedentary behaviour in the UK. Journal of Epidemiology and Community Health, 73(7), 625-629.

Howitt, C., Brage, S., Hambleton, I. R., Westgate, K., Samuels, T. A., Rose, A. M. C., \& Unwin, N. (2016). A cross-sectional study of physical activity and sedentary behaviours in a Caribbean population: Combining objective and questionnaire data to guide future interventions. BMC Public Health, 16, 1036.

Kozey-Keadle, S., Libertine, A., Lyden, K., Staudenmayer, J. W., \& Freedson, P. S. (2011). Validation of wearable monitors for assessing sedentary behavior. Med Sci Sports Excerc, 43(8), 1561-1567.

Kozey Keadle, S., Lyden, K., Strath, S. J., Staudenmayer, J. W., \& Freedson, P. S. (2019). A framework to evaluate devices that assess physical behavior. Exercise and Sport Sciences Reviews., 47(4), 206-214.

Lewis, B. A., Napolitano, M. A., Buman, M. P., Williams, D. M., \& Nigg, C. R. (2017). Future directions in physical activity intervention research: Expanding our focus to sedentary behaviors, technology and dissemination. Journal of Behavioral Medicine, 40, 112-126.

Loprinzi, P. D., Pazirei, S., Robinson, G., Dickenson, B., Edwards, M., \& Rhodes, R. E. (2020). Evaluation of a cognitive affective model of physical activity behavior. Health Promotion Perspectives, 10(1), 88-93.

Lyden, K., Kozey Keadle, S., Staudenmayer, J., \& Freedson, P. S. (2017). The activPAL ${ }^{\mathrm{TM}}$ accurately classifies activity intensity categories in healthy adults. Medicine and Science in Sports and Exercise, 49(5), 1022-1028.

Mengesha, M. M., Roba, H. S., Ayele, B. H., \& Beyene, A. S. (2019). Level of physical activity among urban adults and the socio-demographic correlates: A population-based cross-sectional study using the global physical activity questionnaire. BMC Public Health, 19, 1160.

Nigg, C. R., Joi Mateo, D., \& An, J. (2017). Pokémon GO may increase physical activity and decrease sedentary behaviors. Editorial. American Journal of Public Health, 107(1), 37-38.

Orban, K., Edberg, A. K., \& Erlandsson, L. K. (2012). Using a timegeographical diary method in order to facilitate reflections on changes in patterns of daily occupations. Scand J Occup. Ther, 19, 249-259.

Peete Gabriel, K. K., Morrow, J. R., \& Woolsey, A. L. T. (2012). Framework for physical activity as a complex and multidimensional behavior. Journal of Physical Activity and Health, 9(1), 11-18.

Polit, D. F., Beck, C. T. (2010). Nursing research. Appraising Evidence for nursing practice. Seventh Edition. Lippincott, Williams \& Wilkins. 
Prochaska, J. Q., DiClemente, C. C. (1982). Transtheoretical therapy: Toward a more integrative model of change. Psychotherapy: Theory, Research, and Practice, 19(3), 276-288.

Prochaska, J., \& Q., DiClemente, C.C. (1983). Stages and processes of self-change of smoking: Toward an integrative model of change. Journal of Consulting and Clinical Psychology, 51(3), 390-395.

Prochaska, J., \& Q., DiClemente, C.C. (1986). Toward a comprehensive model of change. treating addictive behaviors. Edited by William R. Miller and Nick Heather. Pleanum Publishing Corporation. Applied Clinical Psychology, 13, 3-27.

Romeo, A., Edney, S., Plotnikoff, R., Curtis, R., Ryan, J., Sanders, I., Crozier, A., Maher, C. (2019). Can smartphone apps increase physical activity? Systematic review and meta-analysis. Journal of Medical Internet Research, 21(3), e12053.

Rutten, G. M., Savelberg, H. H., Biddle, S. J. H., Kremers, S. P. J. (2013). Interrupting long periods of sitting: Good STUFF. International Journal of Behavioral Nutrition and Physical Activity, 10(1).

Schneider, P. L., Crouter, S. E., Lukajic, O., \& Bassett, D. R. J. R. (2003). Accuracy and reliability of 10 pedometers for measuring steps over a 400-m walk. Medicine and Science in Sports and Exercise, 35(10), 1779-1784.

Strath, S. J., Kaminsky, L. A., Ainsworth, B. E., Ekelund, U., Freedson, P. S., Gary, R. A., Richardson, C. R., Smith, D. T., \& Swartz, A. M. (2013). Guide to the assessment of physical activity: Clinical and research applications a scientific statement from the American Heart Association. Circulation, 128, 2259-2279.
Tudor-Locke, C., Craig, C. L., Brown, W. J., Clemes, S. A., De Cocker, K., Giles-Corti, B., et al. (2011). How many steps/day are enough? For adults. International Journal of Behavioral Nutrition and Physical Activity, 8(79).

Tuso, P. (2015). Strategies to increase physical activity. The Permanente Journal, 19(4), 84-88.

Vähä-Ypyä, H., Vasankari, T., Husu, P., Suni, J., \& Sievänen, H. (2015). A universal, accurate intensity-based classification of different physical activities using raw data of accelerometer. Clin Physiol Func Imaging, 35, 64-70.

Warburton, D. E. R., Nicol, C. W., \& Bredin, S. S. D. (2006). Health benefits of physical activity: The evidence. CMAJ, 174(6), 801-809.

WHO. (2018). Global action plan on physical activity 2018-2030: More active people for a healthier world. Geneva: World Health Organization (https://www.who.int/ncds/prevention/physical-activity/ global-action-plan-2018-2030/en/) Accessed 10 June 2020.

WHO. (2020). WHO guidelines on physical activity and sedentary behavior. World Health Organization. https://www.who.int/publications/i/ item/9789240015128 Accessed 1 Dec 2020.

Publisher's Note Springer Nature remains neutral with regard to jurisdictional claims in published maps and institutional affiliations. 